\title{
Subtidal microphytobenthos: effects of inorganic and organic compound supplies on migration, production, and respiration in a tropical coastal environment
}

\author{
Solveig Bourgeois ${ }^{1}$, Sébastien Hochard ${ }^{1}$, Olivier Pringault ${ }^{1,2, *}$ \\ ${ }^{1}$ UR 103 Camélia, Centre IRD de Nouméa, Promenade Roger Laroque, BP A5, 98848 Nouméa Cedex, New Caledonia \\ ${ }^{2}$ Present address: UMR 5119 Ecolag, Université Montpellier 2, CNRS, IRD, Ifremer Station Méditerranéenne \\ de l'Environnement Littoral 2, rue des chantiers 34200 Sète, France
}

\begin{abstract}
Microphytobenthos (MPB) is an important primary producer in coastal ecosystems. In oligotrophic environments, its activity may be controlled by the availability of organic or inorganic compounds but also by its migration behavior. The objective of this study was to determine, in MPBcolonized subtidal sediments, the consequences of short-term enrichments $(<24 \mathrm{~h})$ of organic (alanine, glutamate, and glucose) and inorganic (ammonium, phosphate) compounds on MPB vertical migration and metabolisms, net production (NP), areal gross production (AGP), and community respiration (R). Two contrasting stations located in the southwest lagoon of New Caledonia were investigated: 1 under strong anthropogenic influence and 1 under more oceanic influence. Both stations were dominated by epipelic diatoms. Differences in net primary production were explained by diurnal variation of MPB biomass at the sediment surface, showing the importance of MPB migration in the functioning of these subtidal environments. However, a stimulation or inhibition of MPB migration did not necessarily impact the net primary production of the system; this strongly depends upon the interactions between the autotrophic and heterotrophic compartments, the latter being controlled by the environmental conditions. For the station under low anthropogenic influence, AGP and R were both significantly stimulated by alanine, glucose, and ammonium, and significantly inhibited by phosphate. The similar responses of AGP and R to enrichments suggest that autotrophs and heterotrophs were tightly coupled. Conversely, in the station under strong anthropogenic influence, AGP and R responded differently. Addition of ammonium inhibited AGP without having an impact on $\mathrm{R}$, whereas addition of phosphate inhibited R whilst having no measurable effect on AGP. In this station, the coupling between autotrophs and heterotrophs was weakened, suggesting that the carbon demand of the heterotrophic compartment is probably sustained by the supplies of allochthonous organic matter rather than by exudates from the autotrophic compartment.
\end{abstract}

KEY WORDS: Nutrients · Amino acids · Glucose · Autotroph-heterotroph coupling · Oxygen microelectrode $\cdot$ Reflectance

\section{INTRODUCTION}

The term 'microphytobenthos' (MPB) is used to describe the unicellular photosynthetic eukaryotic algae and prokaryotic cyanobacteria that live in association on the sediment surface (MacIntyre \& Cullen 1995). Heterotrophic and chemoautotrophic bacteria are also closely associated with this community (Stal et al. 1985), which forms a greenish or brownish layer on the sediment surface in intertidal and subtidal shallow ecosystems. In coastal environments, MPB plays an important role in ecosystem functioning. Through its photosynthetic activity, MPB significantly contributes to primary production, and it is responsible for more 
than $50 \%$ of the total primary production in some shallow waters (Underwood \& Kromkamp 1999). Moreover, MPB also plays an important role in the regulation of nutrient fluxes at the water-sediment interface and thus forms an active filter, reducing the supply of nutrients to the water column (Sundbäck et al. 1991). MPB excretes extracellular polymeric substances (EPS; Goto et al. 1999, de Brouwer \& Stal 2001, Underwood \& Paterson 2003) and thus plays an important role by stabilizing the sediment through the reduction of resuspension and erosion (Miller et al. 1996). Excretion of organic compounds by MPB can also represent an important source of carbon for heterotrophic bacteria (Goto et al. 2001, Cook et al. 2007, Bellinger et al. 2009), and grazing of MPB can be an important food source for the higher trophic levels (Miller et al. 1996).

MPB dominated by epipelic diatoms and euglenids is characterized by an endogenous rhythm of vertical migration (Serôdio et al. 1997). This process is well known for MPB inhabiting intertidal sediments, but it has been only recently observed for MPB inhabiting subtidal sediments (Longphuirt et al. 2006). In intertidal environments, the rhythm of vertical migration of MPB is triggered both by the tidal period and by the diurnal period (Consalvey et al. 2004), whereas in subtidal sediments, the diurnal period seems to represent the main trigger for up- and downward migration (Longphuirt et al. 2006). Migration has strong ecological implications in the sediment functioning. It controls the availability of actively photosynthesizing MPB biomass on short time scales, and consequently the shortterm variability of the MPB primary production (Serôdio et al. 2001). If downward vertical migration represents an efficient manner to escape adverse hydrodynamic conditions in intertidal environments, such a hypothesis is not applicable to for subtidal environments. Other driving factors are required to explain the downward migration of MBP while optimum light conditions for photosynthesis still prevail at the sediment surface. For example, downward migration can be an adaptive process developed by cells in order to access high nutrient concentrations deeper in the sediment after having replenished their intracellular organic carbon reserves owing to photosynthesis at the sediment surface (Underwood et al. 2005). This hypothesis is supported by the experimental study of Kingston (2002), which showed a positive response of vertical migration to nutrient enrichment of subsurface sediment in intertidal environments.

As MPB is associated with bacteria, it represents an association between autotrophs and heterotrophs. Activity of MPB-colonized sediments can be limited by environmental factors. The limitation will depend on the considered compartment. Autotrophs can be limited by light and nutrients, whereas heterotrophs are limited by nutrients and organic compounds. Most studies aimed at determining the limiting factors of MPB have used the enrichment approach, with enrichments performed under long-term conditions, several days to 1 wk (Dizon \& Yap 2003, Cook et al. 2007), or even longer, several weeks to several months (Pinckney et al. 1995, Armitage et al. 2006). For example, Dizon \& Yap (1999) showed an increase in the photosynthetic yield of the MPB during a $1 \mathrm{wk} N+\mathrm{P}$ enrichment. Armitage et al. (2006) studied the long-term response (several months) of benthic microalgal communities to nutrient enrichment in a bay in Florida (USA). Using this long-term approach, they showed that the benthic assemblage exhibited different responses to nutrient addition as a function of their location in the bay and the prevailing environmental conditions, with a $\mathrm{P}$ and $\mathrm{N}$ limitation in the eastern part of the bay and no response to $\mathrm{P}$ or $\mathrm{N}$ addition in the western part.

However, a major drawback of long-term incubation studies is that, due to unavoidable community changes, uncertainties remain about the real requirements of the original community (Paerl et al. 1993). To avoid this problem, a process that underlies growth (e.g. primary production) can be quantified during short-term incubations instead (Ludwig et al. 2006). To our knowledge, very few studies have assessed the short-term effects of potentially limiting or inhibiting compounds on MPB functioning. Clavier et al. (2005) studied the response to short-term addition (1 to 2 d) of ammonia on MPB in the southwest lagoon of New Caledonia using in situ benthic enclosures. Using this approach, they showed that net production of MPB in these tropical sediments was stimulated by ammonia. Using ex situ incubations (<6 h), Ludwig et al. (2006) showed that gross photosynthesis and respiration in microbial mats of a shallow inland lake were limited by organic nitrogen and inorganic phosphate.

The goal of this work was to determine if some key compounds (organic and inorganic) control MPB migration and metabolisms (net production, NP; areal gross production, AGP; and community respiration, R) in a tropical shallow subtidal environment, the southwest lagoon of New Caledonia. For that purpose, we used the combination of oxygen microsensors with reflectance measurements, which permit the quantification of the short-term effects $(<24 \mathrm{~h})$ of compound additions, as well as distinguishing the effects on the 3 main processes (AGP, NP, and R) that govern the functioning of MPB. This approach was used to test the hypothesis that the addition of limiting or inhibiting compounds to MPB will result in an increase or decrease in activity observable within several hours following compound addition. Two different sites were studied, one near an outlet that receives sewage 
waters (Clavier et al. 2005) and the second located in the middle of the lagoon considered to be minimally affected by human activity (Jacquet et al. 2006). We anticipated, as underlined by Armitage et al. (2006), that the response to short-term enrichment would differ as a function of site and of the ambient concentrations of nutrients and organic matter.

\section{MATERIALS AND METHODS}

Study site and sampling procedure. MPB-colonized sediments were collected in the southwest lagoon of New Caledonia (Fig. 1) from 6 February to 4 April 2008. The southwest lagoon of New Caledonia includes the urban site of Nouméa and its surrounding coastal zones $\left(22^{\circ} 10^{\prime}\right.$ to $22^{\circ} 35^{\prime} \mathrm{S}$ and $166^{\circ} 00^{\prime}$ to $166^{\circ} 45^{\prime} \mathrm{E}$ ), which represent a sector of $2066 \mathrm{~km}^{2}$. The average depth of the lagoon is $20 \mathrm{~m}$, and the amplitude of the diurnal tide is $0.80 \mathrm{~m}$. Reef structure only accounts for $5 \%$ of the total surface, with the rest mostly soft bottom sediments. This oligotrophic system is subject to marked terrigenous and anthropogenic influence (Fernandez et al. 2006, Migon et al. 2007).
Two contrasting stations were sampled. The Anse Vata bay station (AV) is a shallow station $(5 \mathrm{~m})$ in the vicinity of a wastewater outfall. Stn M03, situated $4 \mathrm{~km}$ offshore at $23 \mathrm{~m}$ depth, is located in the center of the lagoon and is under less anthropogenic influence. Both stations were devoid of macrophytes, and benthic primary production was essentially ensured by MPB. Microscope observations indicated that MPB was dominated by epipelic pennate diatoms at both stations, and no significant changes in MPB community structure were observed during the sampling period.

The day before the experiments, sediment cores were gently collected by scuba diving, using transparent PVC tubes $(5.4 \mathrm{~cm}$ internal diameter). The water sediment interface was preserved during sampling with a 5 to $6 \mathrm{~cm}$ water column above the sediment surface. Samples were conserved in a cool box during transport to the laboratory $(<2 \mathrm{~h})$, where they were acclimated under the same conditions as described in the incubation procedure. Samples of sediment $(2.6 \mathrm{~cm}$ diameter) were collected to measure chl a $(\mathrm{n}=4)$. In addition, $500 \mathrm{ml}$ and $10 \mathrm{l}$ of sea water were collected above the sediment surface for nutrient concentration measurements and core incubation, respectively. This

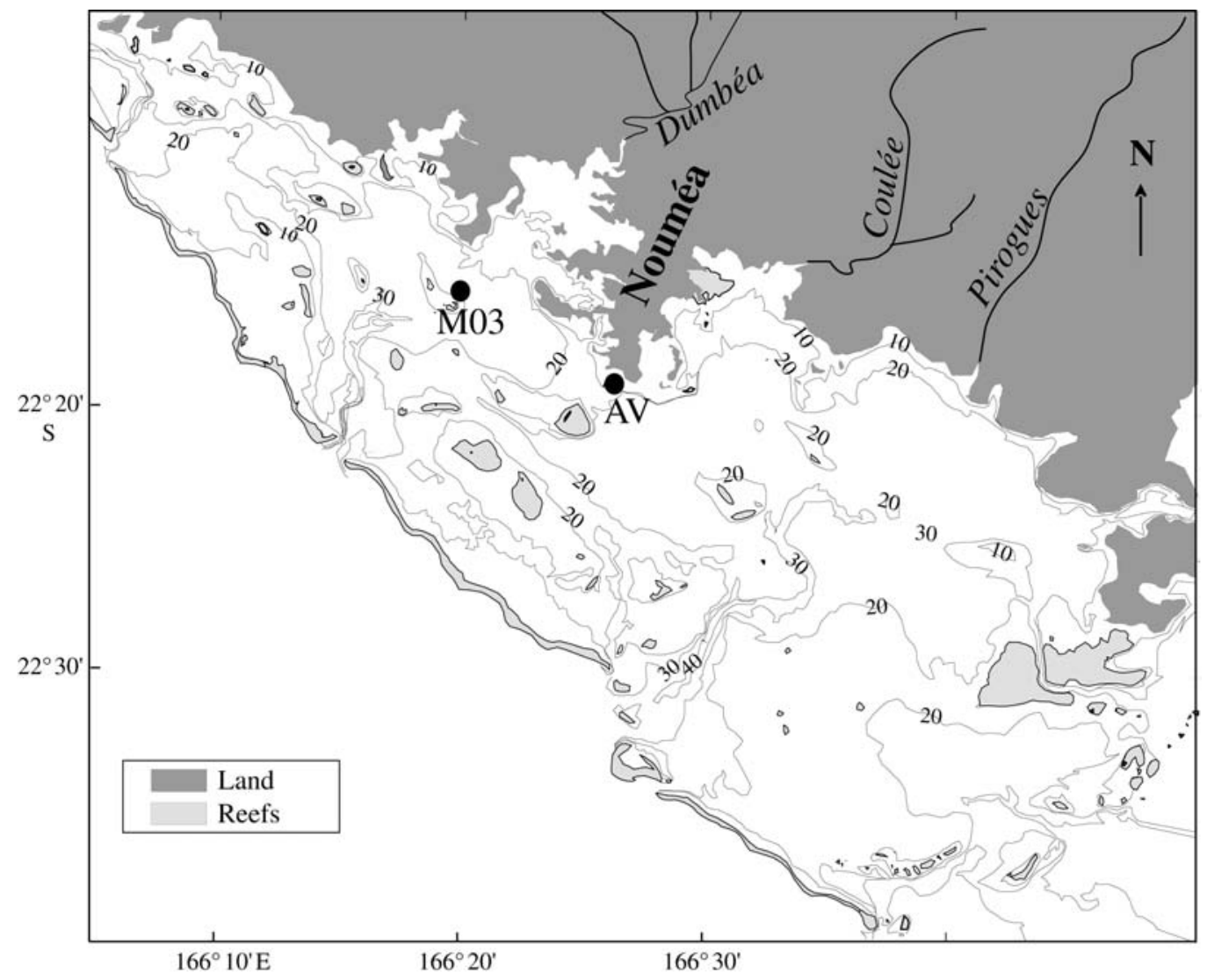

Fig. 1. Study site, showing the 2 sampling stations: AV (Anse Vata, close to shore with $5 \mathrm{~m}$ water depth) and MO3 (4 km off-shore station, $23 \mathrm{~m}$ depth) 
sampling procedure was systematically carried out for each tested compound.

Incubation procedure. Sediment cores were incubated at the laboratory under constant light intensity and temperature simulating in situ conditions. The light period was fixed to reproduce the in situ sunrise and sunset times. Light was provided by a halogen lamp (Schott KL 2500 LCD). The irradiance at the sediment surface measured by a LiCor quantum sensor was set to 175 and $85 \mu \mathrm{mol}$ photons $\mathrm{m}^{-2} \mathrm{~s}^{-1}$ for Stns AV and M03, respectively. These light levels corresponded to average morning irradiances observed in situ at the sediment surface, ensuring that MPB experienced no photoinhibition. Sediment cores were incubated in a 'flow cell' (Epping et al. 1999). The sediment was pushed up gently to the rim of the liner, and the core was inserted from below through the bottom of the flow cell. In this way, the sediment surface was flush with the upper surface of the bottom plate of the flow cell. The flow cell with the sediment core was placed in an aquarium filled with $10 \mathrm{l}$ of seawater from the sampling site, which was continuously bubbling with air and thermostated at in situ temperature (26 to $28^{\circ} \mathrm{C}$, depending on the sampling time and station). A laminar water flow $\left(1 \mathrm{~cm} \mathrm{~s}^{-1}\right)$ in the chamber was created by feeding the inflowing water through a perforated wall upstream of the sample. The water depth above the sediment surface was $3 \mathrm{~cm}$. More details about the flow cell can be found in Epping et al. (1999). Migration measurement. The vertical migration of MPB was continuously monitored by measuring the time course of the surface reflectance using the protocol described by Serôdio et al. (2006). Reflectance spectra were measured using a fiber optic spectrophotometer (USB2000-VIS-NIR, Ocean Optics). Reflectance was recorded over the 350 to $1000 \mathrm{~nm}$ bandwidth with a sampling spectral resolution of $0.38 \mathrm{~nm}$, using a $125 \mathrm{~mm}$ diameter fiber optic. The light probe (acceptance half angle of $11^{\circ}$ ) was positioned perpendicularly to the sediment surface at a fixed distance of $3 \mathrm{~cm}$, which allows the migration monitoring on ca. $1 \mathrm{~cm}^{2}$ of sediment surface. Reflectance measurements were simultaneously conducted with oxygen measurements, and the light probe was placed at the vicinity of the oxygen microelectrode. The variation in MPB biomass at the sediment surface was tracked by using the normalized difference vegetation index (NDVI) ratio (Serôdio et al. 2006):

$$
\mathrm{NDVI}=\frac{R_{750}-R_{675}}{R_{750}+R_{675}}
$$

where $R_{750}$ and $R_{675}$ represent the reflectance measured at 750 and $675 \mathrm{~nm}$, respectively. An increase in this ratio indicates a migration of MPB towards the surface, whereas a decrease indicates that MPB migrates downwards to the sediment. NDVI was monitored with a 1 min frequency. Following the recommendations of Serôdio et al. (2009), potential effects of natural fluorescence on $R_{675}$ were checked, and no interference was highlighted. To assess possible variation of MPB biomass at the sediment surface from day to day, the amplitude of migration was calculated with the following equation:

$$
\text { amplitude }=\mathrm{NDVI}_{\max }-\mathrm{NDVI}_{\text {min }}
$$

where $\mathrm{NDVI}_{\max }$ represents the maximum value recorded around noon (averaged over $10 \mathrm{~min}$, ca. 10 replicates) and $\mathrm{NDVI}_{\min }$ is the minimum value recorded at the beginning of the day.

Microsensor measurement. NP, AGP, and aphotic R of MPB were measured using an oxygen microelectrode (Unisense) with a guard cathode (Revsbech 1989) mounted on a motorized micromanipulator. The electrode (50 $\mu \mathrm{m}$ tip diameter, response time $<1 \mathrm{~s}$ ) was manually positioned at the sediment surface, and profiles and data acquisition were then controlled by a computer. From the steady state oxygen profiles, output (NP) and input (R) fluxes were calculated according to the procedure described by Kühl et al. (1996). Details of flux calculations can be found in Pringault et al. (2005). Three to 4 steady state oxygen profiles were used to calculate R and NP.

Gross photosynthesis activity (volumetric rate) was measured with the 'light-dark shift' technique (Revsbech \& Jørgensen 1983) at 3 distinct depths (sediment surface, $200 \mu \mathrm{m}$, and $400 \mu \mathrm{m}$ below the sediment surface). Three to 4 measurements were performed at each depth. AGP was calculated by integrating the depth distribution of gross photosynthesis. Within a single addition experiment, all profiles were measured at the same location to allow direct comparison between rates before and after addition according to the procedure described by Ludwig et al. (2006). Because of its small size, spatial heterogeneity in the horizontal dimension is not taken into account with the microelectrode, unless time-consuming multiple sampling is carried out. As a result, it is often difficult to judge if the measurements at the selected spot are a good representative for the average rates of the sediment. Nevertheless, repeatedly measuring concentration profiles at the same point in the microbial biofilms under varying environmental conditions allows us to study the relative impact of the different conditions by a comparative approach (see e.g. Garcia-Pichel et al. 1999, Wieland \& Kühl 2000, Benthien et al. 2004)

Added compounds. To assess the effects of compound addition on metabolic activity (AGP, R, and NP) and migration of MPB, we compared activities measured after several hours of incubation to those measured before compound addition according to the pro- 
tocol described by Ludwig et al. (2006). Since MPB exhibits diurnal changes in biomass due to migration of phototrophs towards the surface, steady state profiles of oxygen were measured when MPB biomass at the sediment surface was maximal, i.e. around noon. As a consequence, the initial measurement (before compound addition) was performed around noon, and the addition of the selected compound was performed at the end of the day (around 18:00 h) to allow a complete diffusion through the active layer of MPB during the night. Steady state profiles of oxygen were measured around noon the next day, ca. $18 \mathrm{~h}$ after compound addition. The effect of a selected compound on MPB migration was assessed by comparing the migration amplitude (Eq. 2) measured the day before to the migration amplitude measured after compound addition.

To take into account the experimental conditions of incubation on MPB metabolism and migration, 2 controls without compound addition were incubated for each station. The added concentrations corresponded to an increase of $10 \times$ (except for glucose, $4 \times$ ) ambient concentrations. Ammonium $\left(\mathrm{NH}_{4} \mathrm{CL}\right.$; final concentration of $\left.\mathrm{NH}_{4}: 10 \mu \mathrm{M}\right)$, phosphate $\left(\mathrm{KH}_{2} \mathrm{PO}_{4}\right.$, final concentration of $\mathrm{PO}_{4}: 0.6 \mu \mathrm{M}$ ), and a combined $\mathrm{N}+\mathrm{P}$ addition were performed. Three organic compounds were also tested: glucose, glutamate, and alanine; added concentrations were defined according to literature and dissolved organic carbon (DOC) concentration. Glucose (1 mM final concentration) was added because it represents the major polymerized sugar constituent (up to $85 \%$ ) of EPS (de Brouwer \& Stal 2001, 2002). Glutamate (100 $\mu \mathrm{M}$ final concentration) was selected because it represents 1 of the major amino acids of microalgae (Granum et al. 2002). Finally, alanine (50 $\mu \mathrm{M}$ final concentration) was tested as it is an amino acid present in lower quantities in microalgae, compared to glutamate (Derrien et al. 1998). Compounds were added in the $10 \mathrm{l}$ of in situ sea water circulating above the sediment surface (see incubation procedure).

Chemical analysis. Chlorophyll concentration in the sediment was measured in the top $0.5 \mathrm{~cm}$. Chl a concentration was obtained by methanol extraction followed by acidification, according to the method used by Underwood (2002). Ammonium concentration was measured fluorometrically according to the protocol of Holmes et al. (1999). The concentration of nutrients $\left(\mathrm{NO}_{2}+\mathrm{NO}_{3}, \mathrm{PO}_{4}\right)$ was measured using an Autoanalyzer III (Bran+Luebbe) according to Raimbault et al. (1990) and Grasshoff et al. (1983), respectively. DOC was measured according to the procedure described by Rochelle-Newall et al. (2008).

Statistics. To test whether a given compound had an effect on metabolic activity (AGP, R, and NP) and migration, the average value obtained after compound addition was compared to the average value measured before compound addition. For each metabolic activity, 3 to 4 steady state oxygen profiles were measured before $\left(T_{0}\right)$ and after $\left(T_{\mathrm{f}}\right)$ compound addition. Significant differences between the replicate treatments and controls were tested using the Statgraphics Centurion XV software package (Statpoint). A 2-way analysis of variance (ANOVA), with time and treatment as fixed factors, was used to test the significance of the differences between treatments in the incubations after checking that the assumptions of the ANOVA were met. When a significant difference was observed, an a posteriori test (Fisher's LSD) was used. Thus, a compound was regarded as having an effect if the ratio of average final (after compound addition) activity / average initial (before compound addition) activity $\left(a c t_{\text {fin }} / a c t_{\text {ini }}\right)$ was significantly $(\mathrm{p}<0.05)$ different from the ratio $a c t_{\text {fin }} / a c t_{\text {ini }}$ averaged from the 2 control values of the corresponding station. For the migration signal, the ratio was calculated with the NDVI amplitude (Eq. 2) averaged over $10 \mathrm{~min}$, ca. 10 replicates.

\section{RESULTS}

\section{Environmental parameters}

Nutrient and DOC concentrations (Table 1) were much higher at the station in the vicinity of a wastewater outfall (Stn AV) with enrichment factors up to 8 for nitrates + nitrites and up to 4 for ammonium and DOC relative to the offshore station (M03). Sediment granulometry was comparable at both sites, with a

Table 1. Physicochemical characteristics of the sampling Stns AV (Anse Vata, close to shore with $5 \mathrm{~m}$ water depth) and MO3 (4 km off-shore station, $23 \mathrm{~m}$ depth), see Fig. 1. Concentrations of $\mathrm{NH}_{4}, \mathrm{NO}_{3}+\mathrm{NO}_{2}, \mathrm{PO}_{4}$, and dissolved organic carbon (DOC) were measured in the water column above the sediment surface. Average ( \pm SD). Pheo: pheopigments; Kd: attenuation coefficient for visible light $(400-700 \mathrm{~nm})$

\begin{tabular}{|lcc|}
\hline & AV & M03 \\
\hline $\mathrm{NH}_{4}(\mu \mathrm{M})$ & $0.79 \pm 0.02$ & $0.24 \pm 0.02$ \\
$\mathrm{PO}_{4}(\mu \mathrm{M})$ & $0.13 \pm 0.04$ & $0.038 \pm 0.02$ \\
$\mathrm{NO}_{3}+\mathrm{NO}_{2}(\mu \mathrm{M})$ & $0.82 \pm 0.03$ & $0.104 \pm 0.01$ \\
$\mathrm{DOC}(\mu \mathrm{M})$ & $265.2 \pm 0.83$ & $66.1 \pm 1.1$ \\
$\mathrm{Chl} a\left(\mathrm{mg} \mathrm{m}^{-2}\right)$ & $26.9 \pm 10.1$ & $20.5 \pm 4.8$ \\
Pheo $\left(\mathrm{mg} \mathrm{m}^{-2}\right)$ & $31.2 \pm 14.1$ & $35.1 \pm 10.5$ \\
$\%$ Pheo & $53.4 \pm 10.7$ & $62.4 \pm 6.95$ \\
Average Kd $\left(\mathrm{m}^{-1}\right)$ & 0.4 & 0.09 \\
Depth $(\mathrm{m})$ & 5 & 23 \\
$\%$ Mud & 21.3 & 33.9 \\
$\%$ Sand & 28.9 & 39.2 \\
\% CaCO & 85.9 & 86.1 \\
\hline
\end{tabular}


mud fraction around $30 \%$. Despite different localization and depths, biomass of MPB and concentration of pheopigments were similar at both sites (chl a: 26.9 and $20.5 \mathrm{mg} \mathrm{m}^{-2}$; pheopigments: 31.2 and $35.1 \mathrm{mg} \mathrm{m}^{-2}$ for Stns AV and M03, respectively).

Inverted-microscopy observations indicated that MPB was dominated by epipelic pennate diatoms at both stations, and no significant changes in the MPB community structure were observed during the sampling period.

\section{Migration during the day at constant light}

The time course of NDVI and of NP during the day under constant light for Stns M03 and AV is shown in Fig. 2. At both stations, the migration signal exhibited a bell-shaped time course. Maximal values for NDVI were recorded around noon for Stn AV and slightly earlier for Stn M03. The signal maximum was present during 1 to $2 \mathrm{~h}$, and thereafter decreased back to a value slightly higher than that measured at the beginning of the photoperiod. Under constant light, for both sites, NP rates also exhibited a clear bell-shaped variation during the day, which closely matched the appearance of the biomass at the sediment surface. A few minutes after the onset of light, the sediment was net heterotrophic $\left(-0.025\right.$ and $-0.045 \mathrm{nmol} \mathrm{O}_{2} \mathrm{~cm}^{-2} \mathrm{~s}^{-1}$ for Stns AV and M03, respectively). It then became progressively net autotrophic with positive oxygen fluxes, reaching maximal values around noon. Thereafter the signal decreased, but not as sharply as the morning increase. For both stations, a linear relationship ( $\mathrm{r}=$ 0.912 and $r=0.975$ for Stns AV and M03, respectively) was observed between the changes in MPB biomass (NDVI) and the variations in NP (Fig. 2B,D).

\section{Effects of compound addition on migration}

The method used to assess the effects of different compound additions on MPB migration is based on the comparison with the control experiments. Two control experiments were carried out for each station, and migration signals were monitored during 2 consecutive days (Fig. 3A,C). For each station, migration signals in
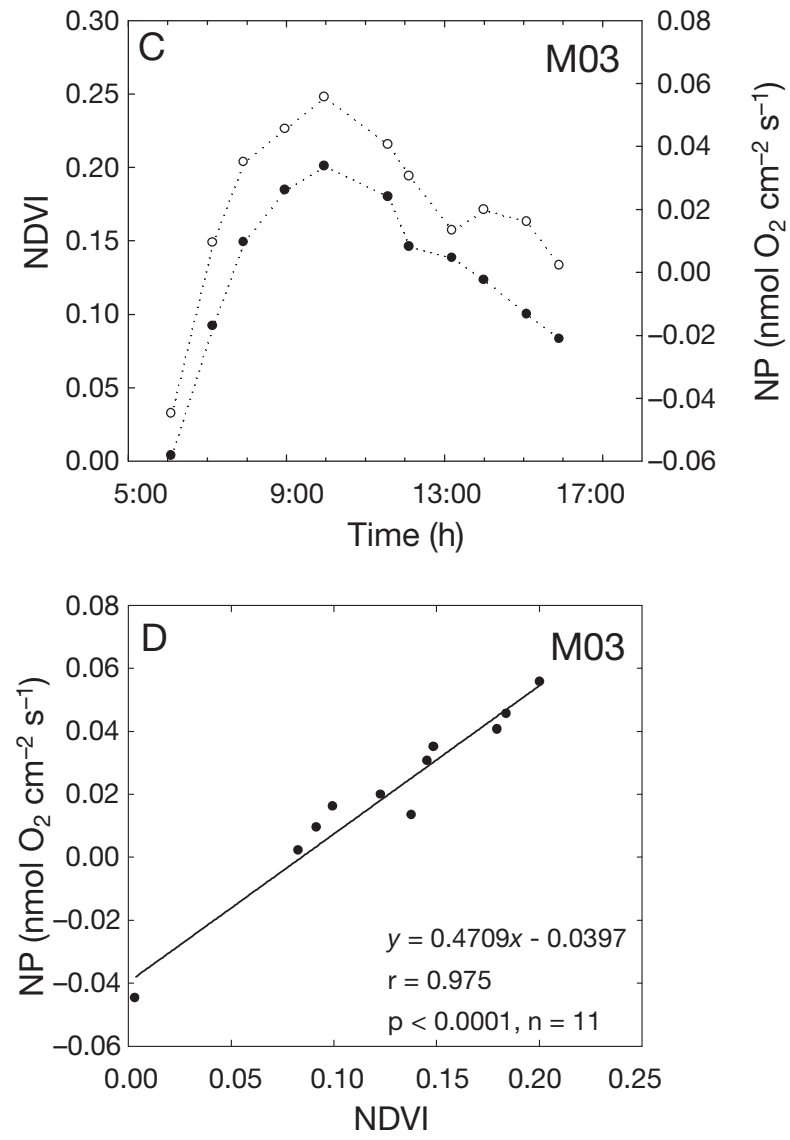

Fig. 2. Migration and net production (NP) during the day at a constant light intensity for $(A, B)$ Stn $A V$ and $(C, D)$ Stn $M O 3$. (A,C) Time course of the normalized difference vegetation index (NDVI closed circles) and NP (open circles) at constant light intensity. 

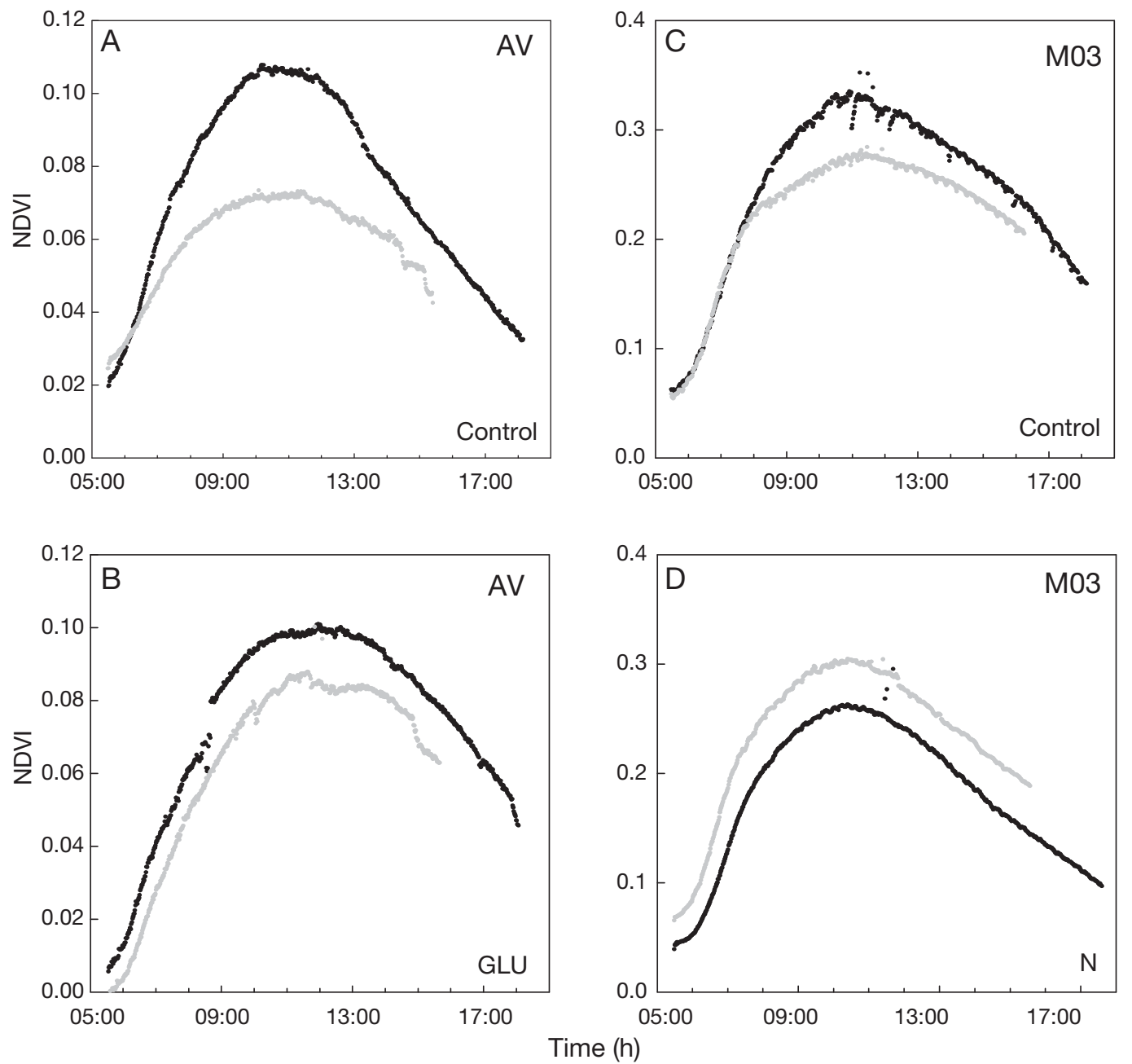

Fig. 3. Migration responses to the addition of selected substances, examples of the normalized difference vegetation index (NDVI) signal as a function of time at Stns M03 and AV for 2 consecutive days. Black (grey) curves represent the migration signal on the first (second) day. $(A, C)$ control experiment; (B) glutamate (GLU) and (D) ammonium (N) added at the end of the first day

the control experiments showed relatively similar trends. Migration signals recorded early in the morning were the same for both days; however, the second day maximum values were invariably lower. The difference in migration amplitude was more pronounced for Stn AV (Fig. 4A), where the value recorded for the second day represented $48 \pm 3 \%$ of the amplitude measured on the first day, compared to $86 \pm 3 \%$ for Stn M03 (Fig. 4C). In comparison, Fig. 3B,D shows the time course of the migration signal during 2 consecutive days, but with ammonium addition at Stn M03 (Fig. 3D) and glutamate addition at Stn AV (Fig. 3B). Ammonium addition at Stn M03 resulted in a positive offset visible at the beginning of the photoperiod. The NDVI maximal value was higher than observed before ammonium addition, indicating that migration was stimulated by the ammonium addition. Similarly, glutamate addition at Stn AV (Fig. 4D) resulted in a stim- ulation of migration since the change in the amplitude of migration from day to day was significantly higher than observed for the control experiment. The responses of the migration amplitude as a function of the different added compounds for Stns AV and M03 are synthesized in Fig. 4. A clear positive effect of ammonium addition was observed for both stations with a migration amplitude ratio (final/initial) $>1$ $(1.119 \pm 0.010$ and $1.072 \pm 0.014$ for Stns AV and M03, respectively). Glutamate, glucose, and $\mathrm{N}+\mathrm{P}$ also resulted in a stimulation of migration at Stn $A V$, with the migration amplitude ratio $<1$ but significantly higher than the control value (Fig. 4B). None of the tested compounds resulted in an inhibition of migration for Stn AV, while glutamate, glucose, and phosphate resulted in a significant decrease (relative to the control value) of the migration amplitude ratio for Stn M03 (Fig. 4D). 

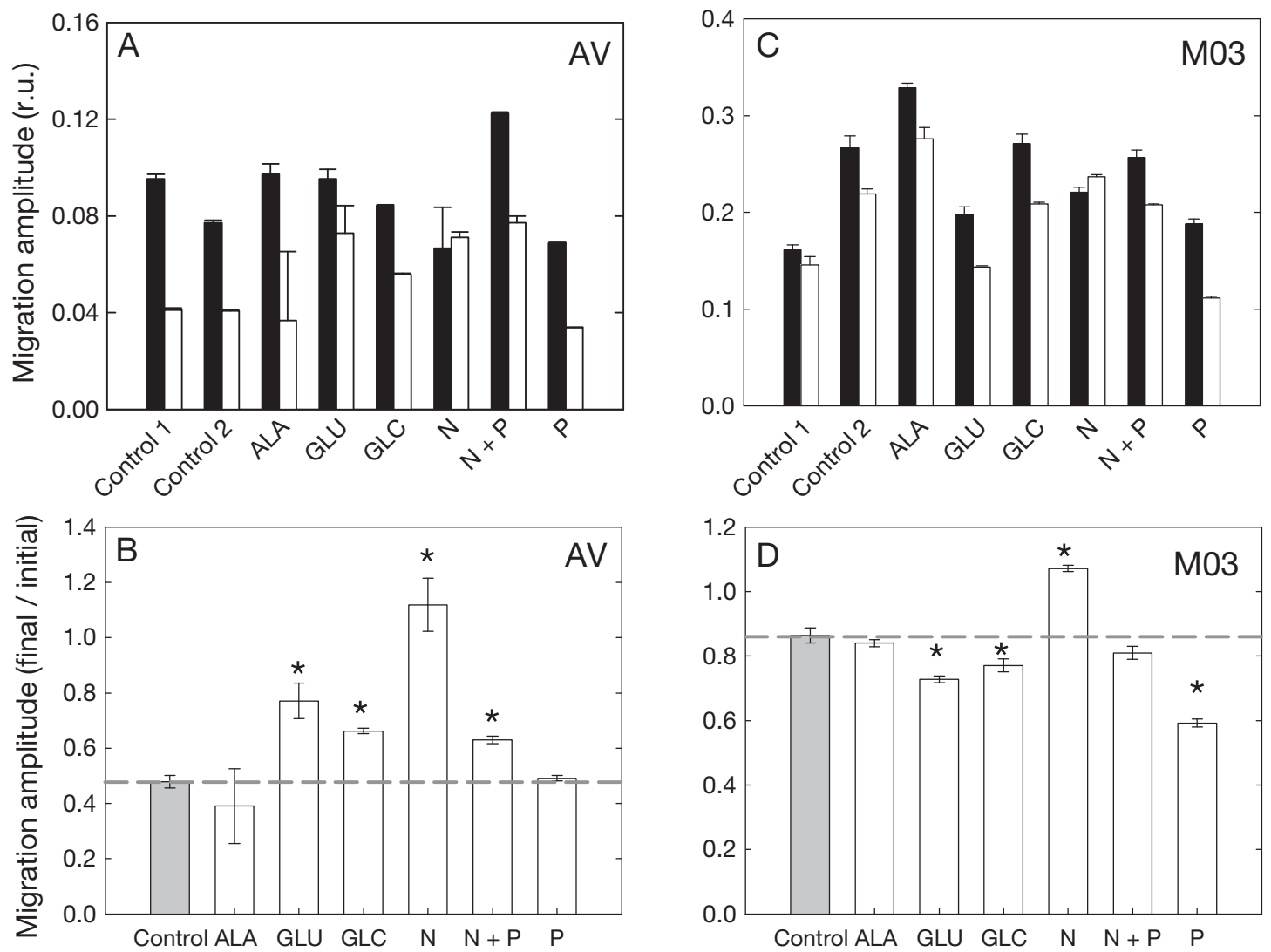

Fig. 4. Effect of inorganic and organic compounds on migration. (A,C) Migration amplitude before (closed bars) and after addition (open bars), mean $\pm \mathrm{SD}(\mathrm{n}=10)$. ( $\mathrm{B}, \mathrm{D})$ Final amplitude $\left(T_{\mathrm{f}}\right) /$ initial amplitude $\left(T_{0}\right)$ ratio. Errors bars represent the $95 \%$ confidence interval. Asterisk denotes a significant difference from the control $(\mathrm{p}<0.05)$. Horizontal dotted line represents the ratio observed in the control experiment. A value significantly above this line indicates a stimulation effect, and vice versa for an inhibition effect (see 'Results' for details). ALA: alanine, GLU: glutamate, GLC: glucose, r.u.: relative units

\section{Effect on oxygen profiles and photosynthesis vertical distribution}

The response of the $\mathrm{O}_{2}$ concentration profiles and photosynthesis activities to selected compound additions is given in Fig. 5. The controls exhibited relatively comparable oxygen profiles from day to day for both stations. However, a reduction in photosynthesis was observed on the second day for all depths and for both stations (Fig. 5A,D). The addition of $\mathrm{N}$ and glucose at Stn AV induced a strong decrease of the oxygen peak (Fig. 5B,C). Similarly, addition of alanine provoked also a strong decrease of the oxygen peak at Stn M03 (Fig. 5F). The addition of these compounds resulted in a decrease in photosynthesis. Conversely, the addition of $\mathrm{N}+\mathrm{P}$ at Stn M03 induced an increase in the oxygen peak concomitant with an increase in photosynthetic activity (Fig. 5E).

The oxygen profiles and gross photosynthesis measurements were used to calculate the response of AGP, $\mathrm{NP}$, and $\mathrm{R}$ to compound addition (see Figs. 6, 7, \& 8, respectively).

\section{Effects on AGP}

The control incubation exhibited a decrease of AGP at $T_{\mathrm{f}}$ relative to $T_{0}$ at both stations (Fig. 6). On average, AGP measured on the second day in the control experiment represented $75 \%\left(a c t_{\text {fin }} / a c t_{\text {ini }}=0.75\right)$ and $50 \%$ $\left(a c t_{\text {fin }} / a c t_{\text {ini }}=0.50\right)$ of the initial activity for Stns AV and M03, respectively (Fig. 6B,D). For Stn AV, no stimulation of AGP was observed upon the addition of the tested compounds (Fig. 6A,B). In contrast, at Stn M03 (Fig. 6C,D), alanine, glucose, N, and N+P induced a significant increase in AGP relative to that observed for the control. The highest stimulation was observed for $\mathrm{N}+\mathrm{P}$ addition, with a doubling of the activity relative to the initial value $\left(a c t_{\mathrm{fin}} / a c t_{\mathrm{ini}}=2.01\right)$. Alanine and $\mathrm{N}$ slightly stimulated AGP relative to the initial value $\left(a c t_{\text {fin }} / a c t_{\text {ini }}=1.15\right.$ and $a c t_{\text {fin }} / a c t_{\text {ini }}=1.13$, respectively $)$. Those weak stimulations should be observed in light of the $50 \%$ decrease of AGP observed in the control incubation. A significant decrease of AGP $\left(a c t_{\text {fin }} / a c t_{\text {ini }}=\right.$ 0.25) was observed upon $P$ addition at Stn M03, and upon $\mathrm{N}$ addition at Stn $\mathrm{AV}\left(a c t_{\mathrm{fin}} / a c t_{\mathrm{ini}}=0.57\right)$. 

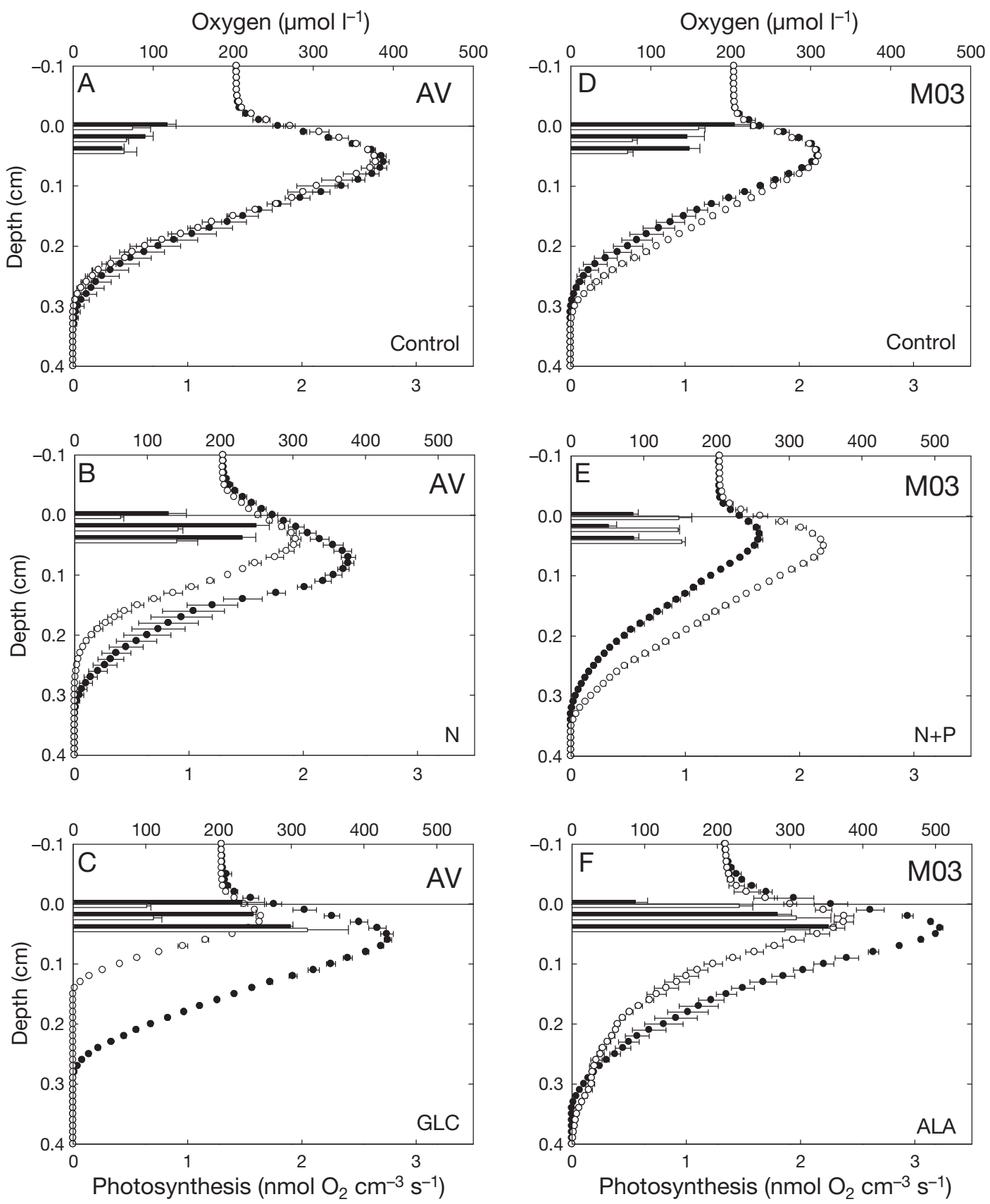

Fig. 5. Metabolism responses to the addition of selected substances. Steady state oxygen profiles (circles) and photosynthesis rates (horizontal bars) measured around noon under initial conditions ( $T_{0}$, closed symbols and bars) and $24 \mathrm{~h}$ later ( $T_{\mathrm{f}}$, open symbols and bars) after compound addition or without any addition (control) for (A-C) Stn AV and (D-F) Stn M03. Mean \pm SD $(\mathrm{n}=3-4)$. GLC: glucose, ALA: alanine. Horizontal line represents the sediment surface

\section{Effects on R}

At $\mathrm{Stn} \mathrm{AV}, \mathrm{R}$ in the controls was similar from day to day (Fig. 7A,B). In contrast, for Stn M03 (Fig. 7C,D), as observed for AGP, laboratory incubation resulted in a significant decrease of $\mathrm{R}\left(a c t_{\text {fin }} / a c t_{\text {ini }}=0.80\right)$. Upon compound addition, no stimulation of $\mathrm{R}$ was observed for Stn AV. In contrast, for Stn M03, the same compounds that resulted in a stimulation of AGP also stimulated R (Fig. 7C,D); however, the stimulation was less marked. $\mathrm{N}+\mathrm{P}$ and $\mathrm{N}$ addition resulted in a similar stimulation of $\mathrm{R}\left(a c t_{\text {fin }} / a c t_{\text {ini }}=1.25\right.$ and $a c t_{\text {fin }} / a c t_{\text {ini }}=1.35$ for $\mathrm{N}+\mathrm{P}$ and $\mathrm{N}$, respectively), whereas a slight but significant stimulation relative to the decrease observed for 

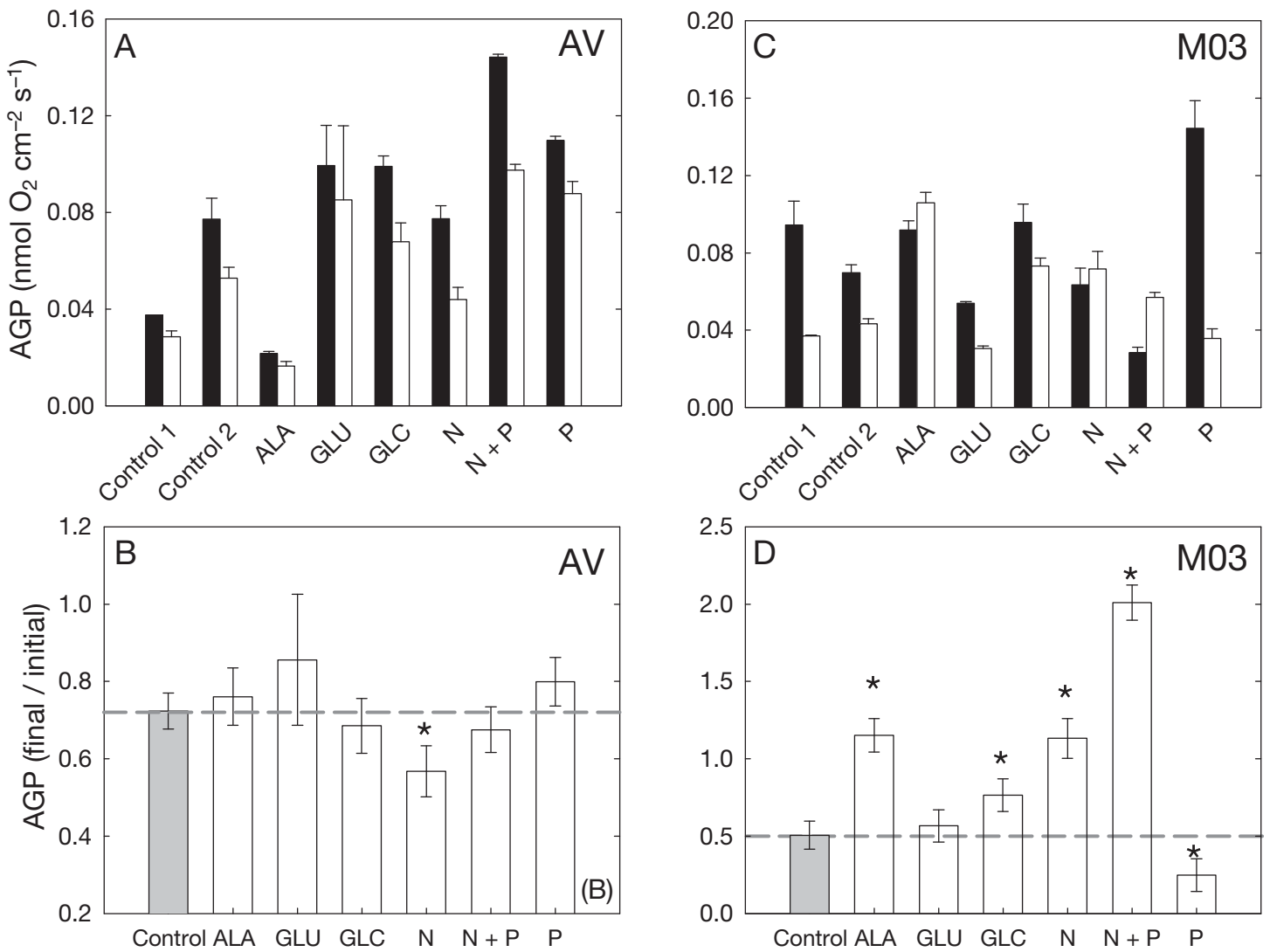

Fig. 6. Effect of inorganic and organic compounds on areal gross photosynthesis (AGP). (A,C) AGP rates before (closed bars) and after addition (open bars), mean $\pm \mathrm{SD}(\mathrm{n}=3-4)$. (B,D) Final activity $\left(T_{\mathrm{f}}\right) /$ initial activity $\left(T_{0}\right)$ ratio. Errors bars represent the $95 \%$ confidence interval. Asterisk denotes a significant difference from the control $(p<0.05)$. Horizontal dotted line represents the ratio observed in the control experiment. A value significantly above this line indicates a stimulation effect, and vice versa for an inhibition effect (see 'Results' for details). ALA: alanine, GLU: glutamate, GLC: glucose

the control was observed for alanine and glucose $\left(a c t_{\text {fin }} / a c t_{\text {ini }}=1.0\right.$ and $a c t_{\text {fin }} / a c t_{\text {ini }}=1.15$, respectively $)$. As observed for AGP, the addition of $\mathrm{P}$ strongly decreased $\mathrm{R}\left(a c t_{\mathrm{fin}} / a c t_{\text {ini }}=0.45\right)$ at Stn M03. This negative effect was observed for Stn AV upon $\mathrm{P}$ addition

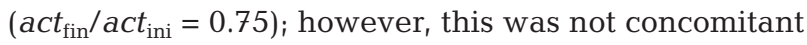
with an inhibition of AGP.

\section{Effects on NP}

NP in the control incubation decreased slightly with 90 and $80 \%$ of the initial value for Stns AV and M03, respectively (Fig. 8). For Stn AV, glutamate, glucose, and $\mathrm{N}+\mathrm{P}$ addition resulted in a strong inhibition of NP, with the addition of glutamate resulting in an NP value of 0 (respiration equals production), whereas before addition, the system was net autotrophic (NP > 0 ; Fig. 8A,B). Interestingly, none of the tested compounds led to a stimulation of NP. In contrast, for Stn M03, the 3 compounds (glucose, $\mathrm{N}$, and $\mathrm{N}+\mathrm{P}$ ) that stimulated both AGP and R also led to a stimulation of NP (Fig. $8 \mathrm{C}, \mathrm{D})$. The addition of alanine, which stimulated both AGP and $\mathrm{R}$, had no effect on NP, implying that $\mathrm{R}$ and AGP must have increased in the same proportions. Conversely, addition of glutamate and $\mathrm{P}$ resulted in a strong significant decrease of $\mathrm{NP}$; however, while $\mathrm{P}$ had an inhibiting effect on AGP and R, glutamate did not significantly affect either process.

\section{DISCUSSION}

\section{Vertical migration and primary production}

Our experiment clearly highlights the fact that the appearance of MPB biomass at the sediment surface was the main driver of sediment net primary production on day time scales. As a consequence, under constant light, MPB net primary production showed a bellshaped evolution during the course of the day (Fig. 2A,C). Indeed, in the morning, the sediment pri- 

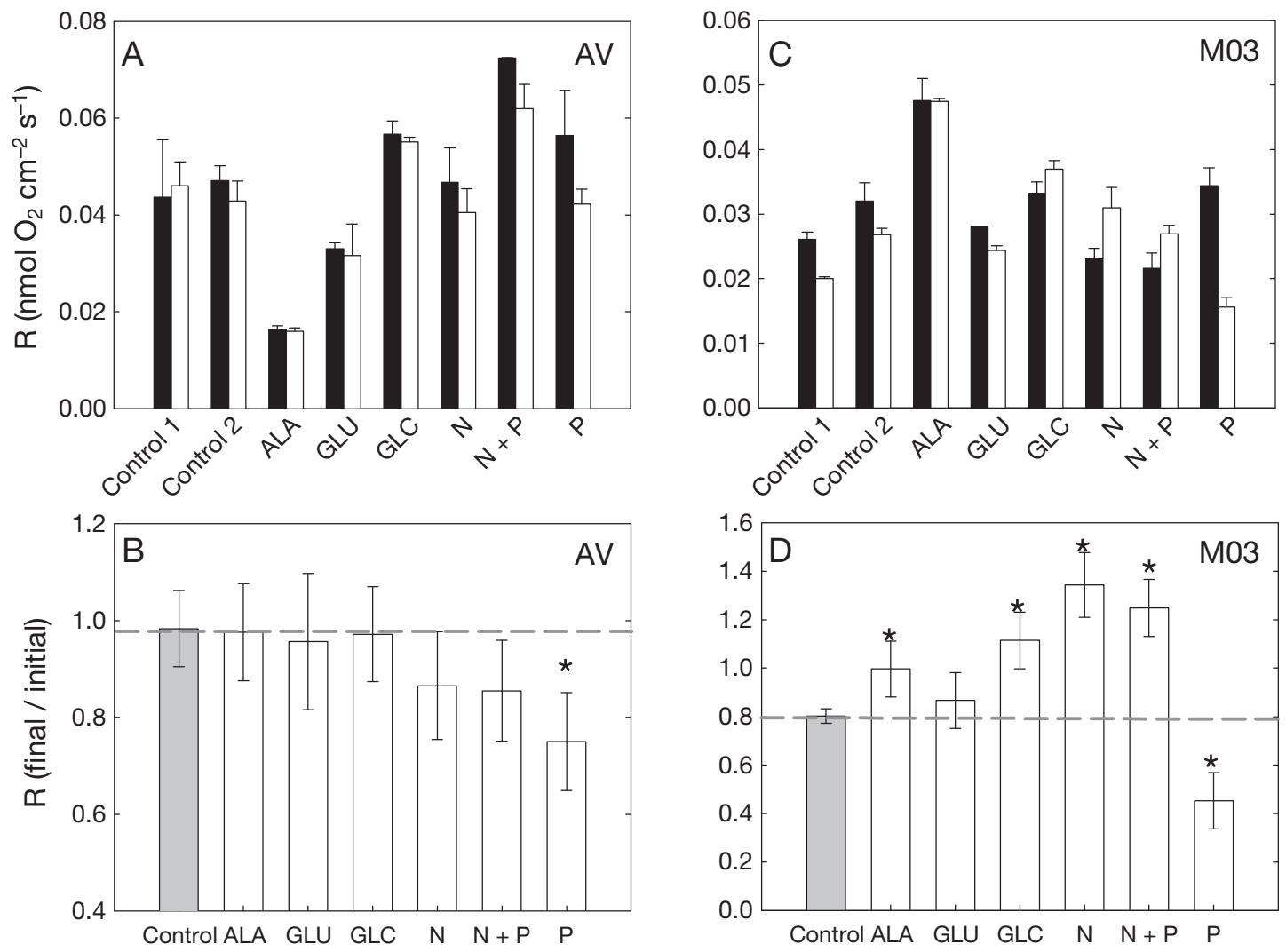

Fig. 7. As in Fig. 6, but showing the effect of inorganic and organic compounds on respiration (R)

mary production rapidly increased concomitant with the appearance of biomass at the sediment surface. The sediment remained net heterotrophic half an hour after illumination and became net autotrophic during the morning. At the end of the day, biomass and primary production decreases were not as sharp as the increase. Generally, some phototrophic biomass was still present at the end of the day, and sediments were still net autotrophic, although with lower oxygen fluxes as compared to mid-day. This might be due to the constant light conditions, which may have delayed the downward migration of MPB or to species-specific variations in the migratory rhythm (Underwood et al. 2005).

It is worth noting that the migration signal and the primary production maximum plateau were very narrow (1 to $2 \mathrm{~h}$ ), indicating that the system was continually modified. This migration pattern and its consequences for benthic metabolism must be taken into account in temporal or spatial comparisons between samples. By concomitantly measuring vertical migration and net primary production under constant light conditions, our results experimentally confirm the theoretical model developed by Longphuirt et al. (2006). In addition, the strong linear relationship between NDVI and NP (Fig. 2) was still observed after com- pound addition, except for glutamate at Stn AV, which resulted in a strong inhibition of NP with rates close to 0 . This underlines the implication of vertical migration on the in situ assessment of the functioning of the coastal sediments colonized by MPB.

\section{Migration response to compound addition}

At both sites, the response of migration to compound additions appears to be complex, with both enhancement and diminution of the migration amplitude signal. There was a clear response of vertical migration to the addition of ammonium at both stations (Fig. 4B,D). More biomass was present at the sediment surface than at the beginning of the photoperiod of the second day, indicating that migration actively responded to the ammonium pulse during the night (Fig. 3B). The addition of phosphate, glutamate, and glucose at Stn M03 resulted in a decrease in the migration signal. The concentration of the added compounds was not sufficient to induce a toxic effect on the MPB metabolism. It is possible that upon organic addition (glutamate and glucose), the decrease in migration might be due to an indirect effect of the organic compounds on 

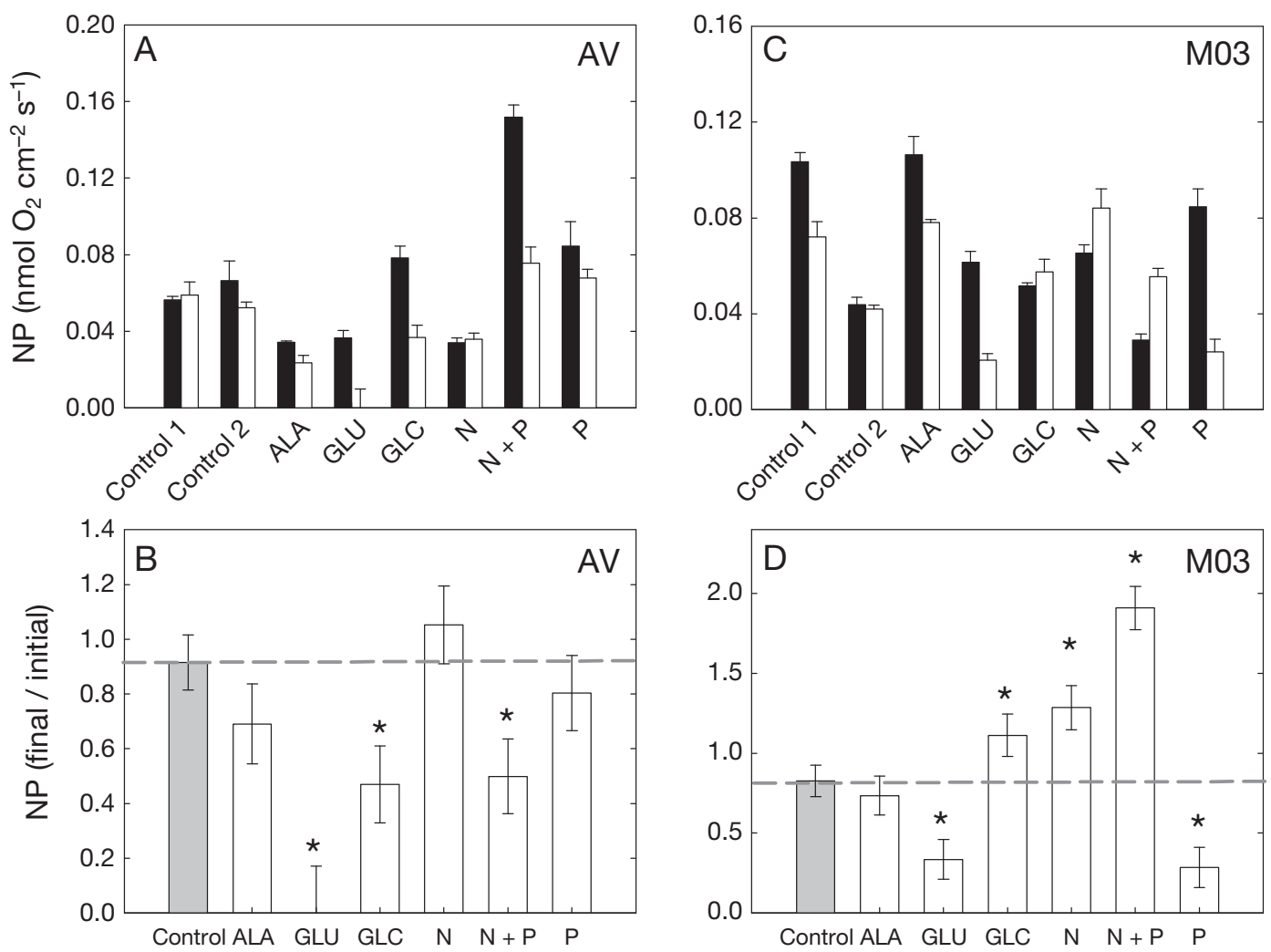

Fig. 8. As in Fig. 6, but showing the effect of inorganic and organic compounds on net production (NP)

the heterotrophic compartment. Heterotrophic bacteria might catabolize glutamate and glucose and produce nutrients than can be directly used by the autotrophic compartment. This bacterially mediated source of nutrients could affect migration behavior by counterbalancing the endogenous rhythm of an upward migration (Longphuirt et al. 2006), thus leading to an apparent inhibition of the migration signal relative to the control. The opposite trends observed for migration upon organic compound addition at both stations suggest that the responses of microalgae depend on the sampling site and the prevailing environmental conditions. Migration is often considered a way of seeking nutrients (Kingston 2002, Underwood et al. 2005). However, the access to nutrients depends on the environmental conditions, but also on the interactions (negative and/or positive) between autotrophs and heterotrophs. Both stations are characterized by strong differences in nutrients and DOC concentrations (Table 1). These differences have important consequences on the strength of the coupling between autotrophs and heterotrophs (see below: section 'Coupling between production and respiration'). As a consequence, this might explain why organic compound addition resulted in opposite trends for migration at the 2 sites.

\section{Stimulation of gross production}

The effects of organic and inorganic compounds on AGP varied as a function of the added compound and the sampling station. At Stn AV, no stimulation of AGP was observed (Fig. 6). In contrast, at Stn M03, AGP was significantly stimulated, relative to the natural variations of the control, by the addition of $\mathrm{N}$, alanine, N+P, and glucose (Fig. 6). The positive response of AGP upon $\mathrm{N}, \mathrm{N}+\mathrm{P}$ and alanine addition would indicate that MPB in this environment was $\mathrm{N}$ limited, which is in agreement with the observation of $\mathrm{N}$ limitation for the phytoplankton compartment in this lagoon (Jacquet et al. 2006).

A hypothesis to explain this stimulation is that the increase in AGP is an indirect consequence of the stimulation of MPB migration. In fact, $N$ enrichments resulted in a stimulation of migration (Fig. 4D) concomitant with a stimulation of AGP. An increase in the migration of microphytobenthic cells towards the sediment surface increases the number of cells that can carry out photosynthesis (Underwood 2002). Secondly, the stimulation of AGP could also be due to an increase in the photosynthetic efficiency as suggested by Kolber et al. (1988). Using short-term additions, Dizon \& Yap 
(1999) found an increase in the photosynthetic yield of MPB as a consequence of N enrichment. Similarly, short-term stimulations of AGP by N-rich organic compounds (alanine) that were not due to variations in biomass due to migration of phototrophic microorganisms have been observed in microbial mats (Ludwig et al. 2006).

The stimulation of glucose on AGP observed at Stn M03 cannot be explained according the 2 abovementioned hypotheses, since AGP was stimulated by glucose addition while migration was significantly inhibited. To explain the stimulation of primary production by an organic compound, Laursen et al. (2002) suggested that the addition of glucose initially stimulates respiration of the heterotrophic compartment. Autotrophic organisms would then exploit the nutrients recycled during the organic matter mineralization by heterotrophs. The stimulation of AGP is thus an indirect effect of R stimulation. The significant stimulation of R upon glucose addition concomitant with a stimulation of AGP observed at Stn M03 supports this hypothesis (Figs. 6C,D \& 7C,D).

\section{Inhibition of gross production}

Only 2 of the tested compounds significantly inhibited AGP: N at Stn AV and P at Stn M03 (Fig. 6). The inhibition of AGP by P at Stn M03 may be an indirect effect of migration. The inhibition of AGP was concomitant with a significant reduction in MPB migration relative to the control (Fig. 4D). As observed for the stimulation of AGP, shifts in phototrophic biomass may result in significant changes in oxygen production that are unrelated to a direct nutrient limitation of the metabolic activity. Alternatively, the inhibition of AGP could be due to a toxic effect of $\mathrm{P}$, where the added concentration exceeded the $\mathrm{P}$ tolerance threshold of the autotrophic compartment. Similar effects were observed in a microbial mat after $\mathrm{P}$ addition (100× natural concentration), and the authors suggested that the added concentration of $\mathrm{P}$ resulted in a reduction of the photosynthetic capacity due to a toxic effect (Ludwig et al. 2006). However, given the very low concentrations of $\mathrm{P}$ added (10× natural concentration), it is unlikely that any $\mathrm{P}$ inhibition occurred in our incubations. The decrease of AGP is probably due to an indirect effect on migration rather than to a toxic effect of $\mathrm{P}$.

At Stn AV, it is worth noticing that AGP decreased under $\mathrm{N}$ addition, whereas migratory activity was stimulated (Fig. 4B). It therefore appears that any increase in photosynthetic activity due to increased biomass was counteracted by an inhibition of AGP by ammonia. A similar inhibition effect for AGP upon $\mathrm{N}$ addition was also observed in microbial mats (Ludwig et al.
2006). To explain this inhibition effect, Ludwig et al. (2006) suggested that ammonium becomes depronated at high $\mathrm{pH}$ values (>8.5), occurring in the photic zone, and enters cells as uncharged $\mathrm{NH}_{3}$. This might affect gross production, since inhibitory effects of $\mathrm{NH}_{3}$ on photosynthetic activity have been observed in marine diatoms (Azov \& Goldman 1982). Our results differ from those obtained by Clavier et al. (2005), who observed a stimulation of AGP after $\mathrm{NH}_{4}$ addition at this site. Nevertheless, as mentioned in 'Materials and methods', we directly measured AGP, whereas Clavier et al. (2005) estimated AGP from NP and R measurements, assuming thus that $R_{\text {light }}$ was equal to $R_{\text {dark }}$. Therefore, comparison of our work with this former study is somewhat delicate.

The response of AGP to compound addition varied as a function of the sampling site. As MPB represents a significant source of carbon for the trophic chain (Miller et al. 1996) and the bacterial compartment (Goto et al. 2001, Cook et al. 2007), we can therefore suppose that any stimulation or inhibition of primary production could have consequences on the functioning of the ecosystem. Nevertheless, the complex interactions occurring between the autotrophic and heterotrophic microorganisms in MPB mean that any stimulation or inhibition of autotrophic cell migration might not necessarily impact upon MBP primary production in the same way. This would depend on the strength of the coupling between the primary producers and the heterotrophic consumers within the MPB consortium.

\section{Coupling between production and respiration}

The coupling between the autotrophic and heterotrophic compartments differed between the 2 stations. This is in agreement with the study of Armitage et al. (2006), who showed that the response of MPB to nutrient enrichments varies as a function of site and prevailing environmental conditions.

At Stn M03, we observed concomitant responses of AGP and R for certain compounds (Figs. 6C,D \& 7C,D), suggesting a degree of coupling between production and $\mathrm{R}$. The link between the 2 processes was observed in the control experiments, where decreases in AGP were paralleled by a similar decrease of R (Figs. 1D, $2 \mathrm{C}, \mathrm{D}, \& 3 \mathrm{C}, \mathrm{D})$. Under these conditions (lower ambient nutrient and DOC concentration), the autotrophic compartment and the heterotrophic compartment were tightly coupled (Ludwig et al. 2006), since NP, which represents the difference between AGP and $R$, remained constant (Fig. 8C,D). Interestingly, concomitant stimulation (with alanine, glucose, $\mathrm{N}$, and $\mathrm{N}+\mathrm{P}$ ) of AGP and $\mathrm{R}$ as well as concomitant inhibition (upon $\mathrm{P}$ 
addition) were observed for this site (Figs. 6C,D \& $7 \mathrm{C}, \mathrm{D})$. The observation of both effects (stimulation and inhibition) strongly supports the hypothesis of a coupling between primary producers and heterotrophic consumers. Stimulation of the heterotrophs by autotrophs can be explained by the exudation of labile organic matter during photosynthetic activity (Epping \& Jørgensen 1996), and primary producers can benefit from the release of nutrients by heterotrophs during organic matter mineralization (Laursen et al. 2002).

Although the coupling between the autotrophic and heterotrophic compartments is clear at Stn M03, it appears to be a rather loose link. As observed by Ludwig et al. (2006), a tight coupling between AGP and R implies that if one of the processes is stimulated or inhibited, the second should exhibit the same response with the same order of magnitude, resulting in constant values for NP (i.e. before and after treatment). In our study, NP was stimulated by the same compounds (except for alanine) which also stimulated both AGP and R (Fig. 8). This means that the increased C produced after the addition of a limiting compound is not entirely used by the heterotrophic compartment. This was not the case for alanine, for which AGP and R were proportionally stimulated, resulting in a constant value for NP.

At Stn AV, we observed a decoupling between AGP and R. In the controls, as observed for M03, AGP decreased during the incubation. Nevertheless, this decrease in primary production was not followed by a decrease in $\mathrm{R}$, suggesting that heterotrophic consumers were not uniquely dependent upon the fresh carbon excreted by the phototrophic compartment. Interestingly, in contrast to M03, none of the selected compounds led to a stimulation of AGP or R. Moreover, when an inhibition was observed for AGP (upon $\mathrm{N}$ addition), R remained unaffected. Similarly, addition of $P$ resulted in an inhibition of $R$ without any direct link to changes in AGP rates. These observations confirm that these processes were not coupled at this site. This decoupling between autotrophs and heterotrophs has also been observed in microbial mats dominated by cyanobacteria, where stimulation of AGP by light increase was not followed by an increase of $\mathrm{R}$ (Pringault et al. 2005).

The presence of a variable coupling between autotrophs and heterotrophs has been also observed between phytoplankton and bacterioplankton (Cole et al. 1988, Morán et al. 2002). Morán et al. (2002) showed that the bacterial carbon demand (BCD) was positively correlated with the dissolved primary production (DPP) of phytoplankton in the open ocean, whereas BCD was much higher than DPP in coastal systems. This suggests that phytoplankton and bacterioplankton are tightly coupled in oligotrophic conditions, with phytoplankton relying on bacterioplankton for nutrient regeneration, whereas bacterioplankton relies on phytoplankton for carbon supply. An increase in carbon and nutrient concentrations results in a less tight coupling between both compartments, each compartment having access to external (allochthonous) nutrient or carbon sources. The impact of external carbon sources on the coupling between autotrophs and heterotrophs has recently been shown experimentally with artificial phototrophic biofilms grown with or without glucose (Ylla et al. 2009). The relationships between extracellular enzyme activity and PS II photosynthetic efficiency showed that the algal-bacterial relationship weakened in glucose-amended biofilms grown in light, because heterotrophic bacteria preferentially use external labile compounds (Ylla et al. 2009). Similarly, the fate of ${ }^{13} \mathrm{C}$-enriched dissolved inorganic $\mathrm{C}$ in stream autotrophic biofilms highlighted tight $\mathrm{C}$ flow between autotrophs and heterotrophs in low nutrient streams while nutrient and DOC enrichments resulted to a disruption of this coupling (Lyon \& Ziegler 2009, Ziegler et al. 2009). This latter situation can be envisaged for Stn AV, since this site is located near an outlet that receives wastewaters from the city of Nouméa. The uncoupling between phytoplankton and bacterioplankton has been also observed at this site (Pringault et al. 2009), and the concentrations of DOC and nutrients are much higher at Stn AV than at Stn M03, located in the middle of the lagoon (Table 1). Therefore, it is likely that the environmental conditions that prevail at Stn AV offer the possibility for the phototrophs and the heterotrophs to access a large spectrum of carbon and nutrient sources (including organic nitrogen and organic phosphate), thus decreasing their interdependency.

\section{Notes on the methodology}

In the present study, the methodology used to estimate AGP, NP, and R of MPB with microelectrodes presents some advantages but also some drawbacks. Generally, R and NP are determined from the oxygen changes over time in the overlying water in sediment cores (Dizon \& Yap 1999, Laursen et al. 2002) or in in situ benthic enclosures (Clavier et al. 2005). AGP is then calculated $(\mathrm{AGP}=\mathrm{NP}+\mathrm{R}$ ) assuming that respiration in the light and respiration in the dark are equivalent. This assumption is subject to caution (Epping \& Jørgensen 1996), as it may result in inaccurate AGP estimation (Lindeboom et al. 1985). In addition, while these approaches take into account the spatial heterogeneity of the sediment, oxygen measurements in the water column represent the net fluxes (NP) between AGP and $R_{i}$ it is therefore impossible to discriminate 
the effects of a limiting or stimulating compound on a selected process. Microelectrode measurements have high spatial resolution and are therefore pertinent for a small space in the biofilm. However, the lack of representativeness for the whole sediment averages is counterbalanced by the possibilities of precisely estimating different metabolic processes involved in oxygen cycling and of discriminating the consequences of a nutrient addition on a defined metabolic process. For example, using the traditional approaches (benthic enclosures and net flux measurements), the effects of glucose at Stn AV would show a clear reduction of NP (Fig. 8). Respiration measured in the dark remained significantly unchanged (data not shown), AGP determined from NP and $R_{\text {dark }}$ would result in a lower value relative to the initial rate. This would suggest that glucose addition resulted in an inhibition of AGP. In contrast, by using oxygen microelectrodes to directly measure AGP, we showed that AGP was unaffected by glucose addition (Fig. 6). The diminution of NP was due to a stimulation of respiration associated with the photic zone $\left(\mathrm{R}_{\text {photic }}\right)$ and not to a significant decrease of gross production.

At both stations, MPB exhibited a diurnal change in biomass due to the migration of phototrophs towards the surface. As a consequence, steady state profiles of oxygen were only observed when MPB biomass at the sediment surface was maximal, i.e. 1 to $2 \mathrm{~h}$ centered around noon. As the accurate estimation of primary production using the light-dark shift technique relies on steady state conditions (Revsbech \& Jørgensen 1983), the possible window for this estimation was short. This very short period of steady state situation means that we could only measure oxygen gross production in 3 distinct zones (surface, $200 \mu \mathrm{m}$, and $400 \mu \mathrm{m}$ below the surface). It is therefore probable that AGP is underestimated, as gross production rates below $400 \mu \mathrm{m}$ were not measured. However, it does not preclude concluding possible effects of a defined compound on AGP, as the underestimation was the same for both measurements (before and after addition). In addition, these time constraints for oxygen measurements implied that measurements of steady state profiles in several spots were not feasible in such a short time. Therefore, all measurements were performed at the same location to allow direct comparison of rates before and after compound addition. While spatial heterogeneity is not taken into account by this approach, the effects of migration on MPB metabolism were clearly assessed. We preferred an approach that takes into account a process that plays a key role in the short-term dynamics of primary production in MPBcolonized sediment. Similar approaches have been used to study the responses of microbial mats to variations of environmental conditions, salinity, tempera- ture, and oil contamination (Garcia-Pichel et al. 1999, Wieland \& Kühl 2000, Benthien et al. 2004)

\section{CONCLUSION}

This study clearly demonstrates that the mechanisms controlling the functioning of MPB-colonized sediments are relatively complex. We showed that migration plays an important role in the functioning of subtidal sediment, confirming what has also been observed in intertidal environments. We also showed that the stimulation or inhibition of MPB migration does not necessarily impact the net primary production of the system, which strongly depends upon the interactions between the autotrophic and heterotrophic compartments. Nevertheless, a stimulation or inhibition of the autotrophic and heterotrophic compartments can have an indirect effect on the migration of phototrophic cells through the release of metabolic by-products that are involved in the control of their migration behavior. This indirect effect on migration will also depend on the coupling and competition between microalgae and bacteria, the latter being controlled by the ambient nutrient and organic carbon concentrations of the ecosystem.

Acknowledgements. This research was financed by the ZONECO program of New Caledonia, the Ministry of Overseas Territories (Ministère de l'Outre Mer), and the French Research Institute for Development (IRD). We thank E. Rochelle-Newall for helpful criticisms on an early version of the manuscript and for English improvements.

\section{LITERATURE CITED}

Armitage AR, Frankovich TA, Fourqurean JW (2006) Variable responses within epiphytic and benthic microalgal communities to nutrient enrichment. Hydrobiologia 569: 423-435

Azov Y, Goldman JC (1982) Free ammonia inhibition of algal photosynthesis in intensive cultures. Appl Environ Microbiol 43:735-739

Bellinger BJ, Underwood GJC, Ziegler SE, Gretz MR (2009) Significance of diatom-derived polymers in carbon flow dynamics within estuarine biofilms determined through isotopic enrichment. Aquat Microb Ecol 55:169-187

Benthien M, Wieland A, de Oteyza TG, Grimalt J, Kuhl M (2004) Oil contamination on a hypersaline microbial mat community (Camargue, France) as studied with microsensors and geochemical analysis. Ophelia 58:135-150

Clavier J, Boucher G, Chauvaud L, Fichez R, Chifflet S (2005) Benthic response to ammonium pulses in a tropical lagoon: implications for coastal environmental processes. J Exp Mar Biol Ecol 316:231-241

Cole J, Findlay S, Pace ML (1988) Bacterial production in fresh and saltwater ecosystems: a cross-system overview. Mar Ecol Prog Ser 43:1-10

Consalvey M, Paterson DM, Underwood GJC (2004) The ups and downs of life in a benthic biofilm: migration of benthic diatoms. Diatom Res 19:181-202 
Cook PLM, Veuger B, Boer S, Middelburg JJ (2007) Effect of nutrient availability on carbon and nitrogen incorporation and flows through benthic algae and bacteria in nearshore sandy sediment. Aquat Microb Ecol 49:165-180

$>$ de Brouwer JFC, Stal LJ (2001) Short-term dynamics in microphytobenthos distribution and associated extracellular carbohydrates in surface sediments of an intertidal mudflat. Mar Ecol Prog Ser 218:33-44

de Brouwer JFC, Stal LJ (2002) Daily fluctuations of exopolymers in cultures of the benthic diatoms Cylindrotheca closterium and Nitzschia sp. (Bacillariophyceae). J Phycol 38:464-472

> Derrien A, Coiffard LJM, Coiffard C, De Roeck-Holtzhauer Y (1998) Free amino acid analysis of five microalgae. J Appl Phycol 10:131-134

> Dizon RM, Yap HT (1999) Short-term responses of coral reef microphytobenthic communities to inorganic nutrient loading. Limnol Oceanogr 44:1259-1267

> Dizon RM, Yap HT (2003) Metabolic changes and compositional shifts in nutrient-enriched tropical reef sediment communities. Sci Mar 67:117-127

Epping EHG, Jørgensen BB (1996) Light enhanced oxygen respiration in benthic phototrophic communities. Mar Ecol Prog Ser 139:193-203

Epping EHG, Khalili A, Thar R (1999) Dynamics of photosynthesis and respiration in an intertidal biofilm. Limnol Oceanogr 44:1936-1948

Fernandez JM, Ouillon S, Chevillon C, Douillet P, Fichez R, Le Gendre R (2006) A combined modelling and geochemical study of the fate of terrigenous inputs from mixed natural and mining sources in a coral reef lagoon (New Caledonia). Mar Pollut Bull 52:320-331

Garcia-Pichel F, Kuhl M, Nubel U, Muyzer G (1999) Salinitydependent limitation of photosynthesis and oxygen exchange in microbial mats. J Phycol 35:227-238

Goto N, Kawamura T, Mitamura O, Terai H (1999) Importance of extracellular organic carbon production in the total primary production by tidal-flat diatoms in comparison to phytoplankton. Mar Ecol Prog Ser 190:289-295

Goto N, Mitamura O, Terai H (2001) Biodegradation of photosynthetically produced extracellular organic carbon from intertidal benthic algae. J Exp Mar Biol Ecol 257:73-86

Granum E, Kirkvold S, Myklestad SM (2002) Cellular and extracellular production of carbohydrates and amino acids by the marine diatom Skeletonema costatum: diel variations and effects of N depletion. Mar Ecol Prog Ser 242: 83-94

Grasshoff K, Ehrhardt M, Kremling K (1983) Methods of seawater analysis. Verlag Chemie, Weinheim

> Holmes RM, Aminot A, Kerouel R, Hooker BA, Peterson BJ (1999) A simple and precise method for measuring ammonium in marine and freshwater ecosystems. Can J Fish Aquat Sci 56:1801-1808

> Jacquet S, Delesalle B, Torreton JP, Blanchot J (2006) Response of phytoplankton communities to increased anthropogenic influences (southwestern lagoon, New Caledonia). Mar Ecol Prog Ser 320:65-78

Kingston MB (2002) Effect of subsurface nutrient supplies on the vertical migration of Euglena proxima (Euglenophyta). J Phycol 38:872-880

Kolber Z, Zehr J, Falkowski P (1988) Effects of growth irradiance and nitrogen limitation on photosynthetic energyconversion in photosystem-II. Plant Physiol 88:923-929

Kühl M, Glud RN, Ploug H, Ramsing NB (1996) Microenvironmental control of photosynthesis and photosyntheticcoupled respiration in an epilithic cyanobacterial biofilm. J Phycol 32:799-812
Laursen AE, Seitzinger SP, Dekorsey R, Sanders JG, Breitburg DL, Osman RW (2002) Multiple stressors in an estuarine system: effects of nutrients, trace elements, and trophic complexity on benthic photosynthesis and respiration. Estuaries 25:57-69

Lindeboom HJ, Sandee AJJ, Vanderdriessche H (1985) A new bell jar microelectrode method to measure changing oxygen fluxes in illuminated sediments with a microalgal cover. Limnol Oceanogr 30:693-698

Longphuirt NS, Leynaert A, Guarini JM, Chauvaud L and others (2006) Discovery of microphytobenthos migration in the subtidal zone. Mar Ecol Prog Ser 328:143-154

> Ludwig R, Pringault O, De Wit R, De Beer D, Jonkers HM (2006) Limitation of oxygenic photosynthesis and oxygen consumption by phosphate and organic nitrogen in a hypersaline microbial mat: a microsensor study. FEMS Microbiol Ecol 57:9-17

Lyon DR, Ziegler SE (2009) Carbon cycling within epilithic biofilm communities across a nutrient gradient of headwater streams. Limnol Oceanogr 54:439-449

> MacIntyre HL, Cullen JJ (1995) Fine-scale vertical resolution of chlorophyll and photosynthetic parameters in shallowwater benthos. Mar Ecol Prog Ser 122:227-237

Migon C, Ouillon S, Mari X, Nicolas E (2007) Geochemical and hydrodynamic constraints on the distribution of trace metal concentrations in the lagoon of Noumea, New Caledonia. Estuar Coast Shelf Sci 74:756-765

Miller DC, Geider RJ, MacIntyre HL (1996) Microphytobenthos: the ecological role of the "secret garden" of unvegetated, shallow-water marine habitats. 2. Role in sediment stability and shallow-water food webs. Estuaries 19: $202-212$

Morán XAG, Estrada M, Gasol JM, Pedros-Alio C (2002) Dissolved primary production and the strength of phytoplankton bacterioplankton coupling in contrasting marine regions. Microb Ecol 44:217-223

> Paerl HW, Joye SB, Fitzpatrick M (1993) Evaluation of nutrient limitation of $\mathrm{CO}_{2}$ and $\mathrm{N}_{2}$ fixation in marine microbial mats. Mar Ecol Prog Ser 101:297-306

Pinckney J, Paerl HW, Fitzpatrick M (1995) Impacts of seasonality and nutrients on microbial mat community structure and function. Mar Ecol Prog Ser 123:207-216

Pringault O, de Wit R, Camoin G (2005) Irradiance regulation of photosynthesis and respiration in modern marine microbialites built by benthic cyanobacteria in a tropical lagoon (New Caledonia). Microb Ecol 49:604-616

> Pringault O, Tesson S, Rochelle-Newall E (2009) Respiration in the light and bacterio-phytoplankton coupling in a coastal environment. Microb Ecol 57:321-334

> Raimbault P, Slawyk G, Coste B, Fry J (1990) Feasibility of using an automated colorimetric procedure for the determination of seawater nitrate in the 0 to $100 \mathrm{nM}$ rangeexamples from field and culture. Mar Biol 104:347-351

> Revsbech NP (1989) An oxygen microsensor with a guard cathode. Limnol Oceanogr 34:474-476

> Revsbech NP, Jørgensen BB (1983) Photosynthesis of benthic microflora measured with high spatial resolution by the oxygen microprofile method: capabilities and limitations of the method. Limnol Oceanogr 28:749-756

Rochelle-Newall E, Torreton JP, Mari X, Pringault O (2008) Phytoplankton-bacterioplankton coupling in a sub-tropical South Pacific coral reef lagoon. Aquat Microb Ecol 50:221-229

> Serôdio J, daSilva JM, Catarino F (1997) Nondestructive tracing of migratory rhythms of intertidal benthic microalgae using in vivo chlorophyll a fluorescence. J Phycol 33: $542-553$ 
Serôdio J, Marques da Silva J, Catarino F (2001) Use of in vivo chlorophyll a fluorescence to quantify short-term variations in the productive biomass of intertidal microphytobenthos. Mar Ecol Prog Ser 218:45-61

Serôdio J, Coelho H, Vieira S, Cruz S (2006) Microphytobenthos vertical migratory photoresponse as characterised by light-response curves of surface biomass. Estuar Coast Shelf Sci 68:547-556

Serôdio J, Cartaxana P, Coelho H, Vieira S (2009) Effects of chlorophyll fluorescence on the estimation of microphytobenthos biomass using spectral reflectance indices. Remote Sens Environ 113:1760-1768

Stal LJ, Van Gemerden H, Krumbein WE (1985) Structure and development of benthic marine microbial mat. FEMS Microbiol Ecol 31:111-125

Sundbäck K, Enoksson V, Granéli W, Pettersson K (1991) Influence of sublittoral microphytobenthos on the oxygen and nutrient flux between sediment and water: a laboratory continuous-flow study. Mar Ecol Prog Ser 74:263-279

Underwood GJC (2002) Adaptations of tropical marine microphytobenthic assemblages along a gradient of light and nutrient availability in Suva Lagoon, Fiji. Eur J Phycol 37:449-462

Underwood GJC, Kromkamp J (1999) Primary production by phytoplankton and microphytobenthos in estuaries.

Editorial responsibility: Rudger de Wit, Montpellier, France
In: Nedwell DB, Raffaelli DG (eds) Advances in ecological research, Vol 29. Academic Press, San Diego, CA, p 93-153

Underwood GJC, Paterson DM (2003) The importance of extracellular carbohydrate production by marine epipelic diatoms. In: Callow JA (ed) Advances in botanical research, Vol 40. Academic Press, San Diego, CA, p 183-240

Underwood GJC, Perkins RG, Consalvey MC, Hanlon ARM, Oxborough K, Baker NR, Paterson DM (2005) Patterns in microphytobenthic primary productivity: species-specific variation in migratory rhythms and photosynthetic efficiency in mixed-species biofilms. Limnol Oceanogr 50: 755-767

Wieland A, Kühl M (2000) Irradiance and temperature regulation of oxygenic photosynthesis and $\mathrm{O}_{2}$ consumption in a hypersaline cyanobacterial mat (Solar Lake, Egypt). Mar Biol 137:71-85

Ylla I, Borrego C, Romani AM, Sabater S (2009) Availability of glucose and light modulates the structure and function of a microbial biofilm. FEMS Microbiol Ecol 69: 27-42

> Ziegler SE, Lyon DR, Townsend SL (2009) Carbon release and cycling within epilithic biofilms in two contrasting headwater streams. Aquat Microb Ecol 55:285-300

Submitted: December 3, 2009; Accepted: June 21, 2010 Proofs received from author(s): July 29, 2010 